\title{
¿Jugamos a los cuentos? Una propuestapráctica de animación a la lectura a través de la Educación Física How do we play to the stories? A practical proposal from animation to reading through physical education
}

Belén Tabernero Sánchez*; BegoñaAliseda García**; Ma José Daniel Huerta*

*Universidad de Salamanca (España), **C.E.I.P.S.O. Salvador Dalí yVelázquez (España)

Resumen. El documento justifica la posibilidad de unir la literatura infantil con el área de Educación Física mediante una propuesta met odológica: «Jugar a los cuentos». Dicha propuesta está basada en el concepto de cuento motor pero insiste en la importancia de la lectura/ comprensión del texto escrito como punto de partida. Posteriormente, se ha realizado una experiencia práctica de 5 sesiones durante dos cursos académ icos aplicando esta propuesta de «Jugar a los cuentos» en un centro de educación infantil. La selección de los cuentos y el diseño de las sesiones prácticas se han realizado respetando y completando el programa de aprendizaje propuesto por las maestras titulares en educación infantil. Por último, se describe una sesión a modo de ejemplo de dicha experiencia. Las conclusiones apuntan que «Jugar a los cuentos» ha resultado ser una propuesta metodol ógica válida para conseguir aprendizajes globales e interdisciplinares a partir de los cuentos y el movimiento.

Palabras clave. Educación Física, etapa infantil, cuento motor, lectura.

Abstract. This paper justifies the possibility of uniting children' s literature in the area of Physical Education through a methodologica 1 proposal: «Playing tales». This proposal is based on the concept of motor story but insists on the importance of reading/understanding of the written text as a starting point. Subsequently, there has been a practical experience of 5 sessions during two academic years by applying this pr oposal of «Playing tales» in a kindergarden. The choice of stories and the design of the practical sessions has been done with full respect and co mpleting the learning program proposed by the teachers holders in early childhood education. Finally , it describes a lesson by way of example of such experience. The findings suggest that «Playing tales» has proved to be a methodological proposal valid to achieve global and interdisciplinary programming based on stories and movement.

Keywords. Physical Education, Kinder garden, Motor S tory, Reading encourage.

\section{Introducción}

¿Jugamos al cuento? Esta es la pregunta con la que tras la breve lectura de un cuento impreso (realizada con la ayuda de un escenario) comenzábamos nuestra sesión de Educación Física. Con las caritas aún ilusionadas por lo relatado y la respuesta al unísono de los 25 niñas y niños con un sonoro «isí!, nos poníamos en acción.

Siempre comenzábamos con una pregunta reveladora que, en cierto modo nos cercioraba de la comprensión del cuento y que además nos introducía en el contenido de la sesión de Educación Física. Estas son algunas de las preguntas y respuestas formuladas en los diferentes cuentos:

- ¿Con qué parte del cuerpo los animales pudieron averiguar el sabor de la luna?La lengua, para el cuento de ¿A qué sabe la luna? (Grejniec, 2011);

- ¿Alguien conoce el nombre de alguna estrella? EI Sol, para el cuento de «La estrella que cayó del cielo» (Robson \& Newsham, 2005);

- ¿Qué siguió leoncito para buscar a su mamá?Las huellas de los animales, para el cuento de «Leoncito se ha perdido» (Marshall, 2006)

- ¿Qué diferenciaba a «Nadarín» de los otros peces del mar? Su

color y que era másrápido nadando que los demás, para el cuento de «Nadarín» (Lionni, 1982).

- ¿Por qué se reían todos los animales de la Jirafa Chufa? Porque no sabía bailar, para el cuento de «Las jirafas no pueden bailar» (Andreae, 2013)

De esta forma, algún personaje, algún escenario o el propio contenido del cuento nos llevaba a descubrir conocimientos de diferentes áreas siempre con el mismo medio: el movimiento corporal. A la vez, este mismo movimiento era definido como «salto» o descrito como «rápido»; y los segmentos corporales integrados en el movimiento eran definidos como «músculos» o descritos como «grandes»; y el desplazamiento corporal era referido como «giro» o presentado como «cooperativo».

El proyecto ¿Jugamos a los cuentos? en Educación Física ha estado formado por 5 cuentos que nos han transportado a diferentes escenarios: la boca, el sistema solar, el mar y la selva. En cada caso, hemos

Fecha recepción: 20-09-15- Fecha envío revisores: 20-09-15- Fecha de aceptación: 10-11-15 Belén Tabernero Sánchez beli@usal.es explotado no sólo los escenarios para aprender conceptos de los mismos, sino también distintas situaciones hilvanadas para llegar a un aprendizaje integral donde se han conectado sensaciones, definiciones y experiencias. No se ha representado ni escenificado ningún cuento desde la idea más extendida en la bibliografía de cuento motor (Bravo \& Pagazaurtundua, 2003; García, 2011; García \& Pérez, 2010; Iglesia, 2008; Otones \& López-Pastor, 2014; Parra, 2008; Ruiz-Omecaña, 2009, 2011; Val \& Laso, 2015; Victoria \& Pérez, 2010; Villegas \& García, 2010; Zagalaz \& Cachón, 2010), sino que la comprensión del cuento y la selección de algún elemento clave del mismo ha sido el punto de partida de la sesión de Educación Física para generar, a partir del mismo una serie de actividades físicas enlazadas con una finalidad global.

\section{Objetivos de la experiencia}

\section{General}

Elaborar y poner en práctica una propuesta de intervención didáctica que permitiera vincular los cuentos infantiles a otros elementos del currículo a través de la Educación Física en la etapa infantil.

\section{Específicos}

Buscar y seleccionar cuentos infantiles cuyo contenido (y/o escenario o protagonista) pueda contribuir al desarrollo de objetivos y competencias de educación infantil según la legislación vigente.

Acercar los cuentos infantiles impresos a los niños y niñas de educación infantil con un método experiencial a través del movimiento corporal consciente.

Diseñar diversas sesiones de Educación Física a partir de algún elemento vinculado a los cuentos infantiles seleccionados, que permitieran adquirir aprendizajes globales de diferentes elementos curriculares de educación infantil.

Desarrollar en centros educativos de infantil las sesiones diseñadas, valorando la experiencia por parte de las maestras/tutoras y los aprendizajes extraídos por los participantes.

\section{Estado de la cuestión}

La sociedad actual, sumida en un cambio constante, reta constantemente al docente a buscar recursos y metodologías que logren entusiasmar al alumnado y conseguir despertar en él su interés por conocer

El juego, la canción y el cuento son medios tradicionales que han demostrado sobradamente su valía en la escuela durante muchas genera- 
ciones (Alías, 2011). Por lo tanto, no se trata de buscar lo imposible, sino adaptar recursos disponibles a las necesidades del momento y a los intereses de los niños y niñas.

La propuesta gira en torno a esta idea: «jugar a un cuentołAlgo tan cercano y sencillo como «generar una sesión de Educación Física a partir de un cuento leído transformándolo en un juego motriz» que logre entusiasmar a los niños y niñas despertando su interés por conocer.

\section{¿Por qué jugar a un cuento infantil? Similitudes y diferencias con el cuento motor}

Los cuentos infantiles

La literatura infantil es un medio de transmisión de conocimiento y se constituye como una experiencia placentera para los niños y niñas, ya que responde a sus necesidades e intereses particulares y les permite construir su propia representación de la realidad. Así, la literatura se convierte en un recurso clave para lograr el pleno desarrollo del pensamiento creativo y favorecer su expresión espontánea ante cualquier actividad del aprendizaje escolar (Escalante \& Caldera, 2008).

Los cuentos, narraciones, fábulas e historias que componen la literatura infantil, son un recurso imprescindible en el contexto educativo. Entre otras características, responden a las necesidades íntimas del niño, aproximan la escuela a la vida, aprovechan elementos del folklore, están repletos de estímulos lúdicos, favorecen el desarrollo del lenguaje y la expresión oral. En este sentido, recogen además ciertas características que los convierten en uno de los materiales pedagógicos más enriquecedores (Méndez-Giménez \& Fernández-Río, 2013; Padial \& SáenzLópez, 2013; Vargas \& Carrasco, 2006), como son:

- Ayuda a comprender el mundo en el que vive el lector y a afrontar lo, por ejemplo mediante la concreción de los temores de los niños (miedo a la oscuridad, a que su mamá desaparezca, a perderse...).

- Proporciona temas, motivos y detalles para nutrir su inspiración (la personificación de animales y objetos, la presencia de un reto, peligro o aventura que los personajes deben afrontar, la magia, la fantasía, etc.), por lo que estimula el desarrollo del pensamiento libre y creativo, al mismo tiempo que divierte y activa la curiosidad.

- Amplia el horizonte intelectual y artístico de los niños y adolescentes, así como su universo social, afectivo, imaginativo y lingüístico.

\section{Cuento motor}

El cuento motor conjuga las características de la literatura infantil los cuentos- y las propias de la práctica motriz (ligadas al juego) (Conde, 1994; Ruíz-Omecaña, 2011; Barrio et al., 2011), siendo ambas realidades cercanas a los intereses de los más pequeños, por lo que desempeñarán un papel fundamental en su desarrollo y aprendizaje.

El origen de los cuentos motores parece encontrarse en la figura de Thulin (1876-1965), creador de los «ejercicios en forma de juego» y de los «cuentos gimnásticos», en un intento por enriquecer las tendencias gimnástico-pedagógicas vinculadas a la educación física infantil (González, Madrera \& Salguero, 2004). Conde (1994) señala que los cuentos motores son historias narradas y participativas, además de divertidas, donde el juego motor se transforma en la estructura esencial para la construcción del pensamiento del niño.

Posteriormente el cuento motor se ha vinculado casi exclusivamente con las escenificaciones y representaciones de las historias narradas en los cuentos, dejando otros elementos cognitivos y de construcción de aprendizaje y pensamiento más descuidados:

«Precisamente, del relato del cuento motor se derivan propuestas de acciones motrices en las que los aprendices participan imitando, representando a los personajes de la historia» (Méndez-Giménez \& Fernández-Río, 2013, p.113).

«Los cuentos motores son cuentos que, al ser narrados y con ayuda de la música, propician una amplitud inherente de movimientos, juegos, simulaciones y dramatizaciones» (Iglesia, 2008, p. 3).

«El cuento motor, es una variante del cuento hablado, podríamos denominarlo como el cuento representado, un cuento jugado, en el cual hay un narrador $\mathrm{y}$ un grupo de alumnos/as que representa lo que dice dicho narradon» (García \& Pérez, 2010, p. 1)

\section{El movimiento corporal: una invitación a la lectura jugando a los} cuentos

Sin lugar a dudas, el reto de la escuela es infundir en los niños y niñas el gusto por la lectura, convertirlo en una actividad entretenida y gozosa, proporcionándoles buenos y hermosos libros en un ambiente cálido y placentero (Escalante y Caldera, 2008). La lectura ha de ser una fuente de aprendizaje, pero no mediante una práctica que enfatice la mecanización del lenguaje, convirtiéndola en una actividad carente de sentido, sino mediante una propuesta que involucre a los alumnos, que les permita disfrutar e interesarse por la lectura.

Además, «la necesidad de la lectura es evidente cuando toda la enseñanza y el aprendizaje están basados en ella» (Parra, 2008, p. 1). Desde el área de Educación Física, podemos contribuir a la mejora de este hábito, mediante dinámicas interactivas y lúdicas propias de nuestras clases -y atrayentes para el alumnado-, conjugadas con las estrategias y conocimientos de esta y de otras materias (interdisciplinariedad). (Bravo \& Pagazaurtundua, 2003; Conde, Arteaga \& Viciana, 1998; Guimaraes, 2009; Rivas \& Terroba, 2010).

Respecto al ámbito motriz, tenemos que superar la concepción de la Educación Física ligada al rendimiento técnico y deportivo ya que esta perspectiva limita el aprendizaje. En este sentido, parece sensato avanzar hacia una educación por medio del movimiento, donde las manifestaciones motrices se entiende como comportamientos completos que permiten la comunicación y liberación de las personas, contribuyendo así al desarrollo integral del individuo ('Grgas \& Carrasco, 2006).

En la etapa infantil, y en estrecha relación con el movimiento, estará el juego, entendido desde su función educativa, como elemento clave del desarrollo psicomotor. Las reflexiones acerca de la importancia del juego en el ámbito educativo son abundantes, pero casi todas concluyen en que para aprender mejor, el proceso debe ser motivador, sin perder su rigor educativo (Padial \& Sáenz-López, 2014).

Considerando todo lo aquí recogido y revisando la literatura (Barrio et al., 2011; Ruiz-Omecaña, 2011; Victoria \& Pérez, 2010) parece ser que unir cuento, movimiento y juego puede ofrecer un buen recurso pedagógico que responda a las necesidades e intereses de los más pequeños, así como a los requerimientos de la actividad docente.

Nuestra propuesta concreta se basa en una herramienta educativa que conjuga la literatura infantil, el movimiento corporal y la comprensión cognitiva de valores y contenidos, orientada a la promoción de aprendizajes interdisciplinares. Además, creemos que permite al alumnado ir más allá de la representación: interpretar cognitivamente la información significativa que se ofrece a cada uno de ellos y traducir motrizmente esa interpretación. En este sentido, entendemos su puesta en práctica ligada a la idea inicial de «cuento jugado o vivenciado», propuesta por Conde (1994) como un método pedagógico que parte de un cuento leído en clase para la puesta en marcha de actividades específicas del área de Educación FísicaAdemás, permite dotar al cuento y al movimiento de un carácter global e interdisciplinar en función del contenido, personajes y escenarios del propio cuento (Cidoncha \& Díaz, 2009).

Así, y teniendo en cuenta nuestra interpretación de los elementos analizados hasta el momento, definimos «Jugar a los cuentos» como: «Una propuesta metodológica que parte de un cuento impreso (leído) a partir del cual se identifica un punto de partida. Dicho punto de partida emana de la comprensión del cuento y es la clave para comenzar un juego pedagógico.A lo largo del juego, los niños y niñas se convierten en protagonistas construyendo un aprendizaje global (especialmente vinculado al movimiento, conocimiento de su cuerpo y sus posibilidades motrices). De esta forma, cada cuento leído se completa con un juego pedagógico; por eso, jugar a un cuento».

Analizaremos brevemente esta noción intentado justificar nuestra elección:

- Hablamos dejuego pedagógico porque planteamos una actividad que facilita la exploración y descubrimiento de nuevos conocimientos de una forma lúdica.

- Está contextualizado en un cuento, no escenificamos la historia, sino que la lectura y comprensión del contenido es el elemento inicial, de 
donde extrapolamos algunos escenarios, acciones, personajes... a partir de los cuales desarrollamos los conocimientos y trabajamos la motricidad.

- Los niños y niñas se convierten eprotagonistas de su aprendizaje pues experimentan diferentes sensaciones, se adentran en paisajes ficticios, se mueven como determinados animales, afrontan y resuelven retos, etc.Además, compartimos con ellos una reflexión final, una puesta en común de la sesión, que permita dialogar sobre los contenidos abordados, explicitándolos.

- Favorecemos el conocimiento del propio cuerpo y de sus posibilidades motrices. Una condición fundamental será el componente motriz de las actividades propuestas, se abordarán contenidos como el conocimiento del propio cuerpo y el de los demás, la orientación, la coordinación, cuestiones de higiene y salud, etc. Aunque el propósito final será el desarrollo integral de los niños y niñas, por lo que en un contexto tan rico como el proporcionado por los cuentos, los conocimientos que podremos abordar serán tantos como podamos imaginar

\section{Desarrollo de la experiencia}

\section{Participantes}

La elaboración, puesta en práctica y valoración del proyecto $\dot{¿} J u-$ gamos a los cuentos? se ha llevado a cabo con la participación de 2 maestras titulares de educación infantil en un centro público de la ciudad de Salamanca, los 50 alumnos y alumnas de $3^{\circ}$ de educación infantil de dicho centro y 2 profesoras externas vinculadas a la Facultad de Educación de la Universidad de Salamanca, especialistas en el área de educación física.

\section{Temporalización}

La propuesta se ha desarrollado durante los cursos académicos 2013/14 y 2014/15 en 2 fases claramente diferenciadas por su momento de aplicación:

a) Fase de preparación/elaboración fuera del aula de infantil. Durante esta etapa (octubre a enero) podemos diferenciar los siguientes pasos:

- Determinación de objetivos para abordar la idea de unificar cuento y educación física en infantil (búsqueda de documentación, lectura y formación específica).

- Localización y reunión con maestras titulares de educación infantil para conocer la posibilidad e interés en la realización del proyecto. Valoración de la programación que seguirían durante el curso para proceder a la búsqueda y selección de cuentos infantiles adaptados a la misma.

- Selección de cuentos infantiles. Los criterios para la selección de los mismos fueron los siguientes:

* Que permitieran adaptar el contenido a lo que los niños/as estaban trabajando en el aula y al currículo.

* Sencillos (en sus contenidos), atractivos (en su presentación impresa) y con un alto contenido de educación en valores.

* Con animales como protagonistas (buscábamos la motivación que despiertan en los niños y desarrollar la empatía hacia ellos) que realizan diferentes movimientos.

En la tabla 1 quedan recogidos los cuentos seleccionados, el momento en el que se desarrolló la sesión sobre cada uno y el proyecto educativo en el que se incluyó y vinculó con la programación seguida por las maestras titulares en educación infantil.

Tabla 1.
Calendario de desarrollo de las sesiones de los diferentes cuentos y proyecto educativo con el
que se vincula.
\begin{tabular}{|c|c|c|c|c|c|}
\hline Cuentos & "Nadarín" & $\begin{array}{c}\text { ¿A qué sabe la } \\
\text { luna?" }\end{array}$ & $\begin{array}{c}\text { "Leoncito se } \\
\text { ha perdido" }\end{array}$ & $\begin{array}{c}\text { "Las jirafas } \\
\text { no pueden } \\
\text { bailar" }\end{array}$ & $\begin{array}{c}\text { "La estrella que } \\
\text { cayó del cielo" }\end{array}$ \\
\hline Mes & Febrero & Marzo & Abril & Mayo & Junio \\
\hline $\begin{array}{c}\text { Proyecto } \\
\text { educativo }\end{array}$ & $\begin{array}{c}\text { "Tierra, } \\
\text { mar y aire" }\end{array}$ & $\begin{array}{c}\text { "El cuerpo: } \\
\text { sensaciones" }\end{array}$ & $\begin{array}{c}\text { "Animales } \\
\text { salvajes" }\end{array}$ & $\begin{array}{c}\text { "Cultura y } \\
\text { costumbres" }\end{array}$ & "El universo" \\
\hline
\end{tabular}

- Diseño y elaboración de las sesiones de Educación Física, según el currículo y programación de educación infantil en el curso en que se iban a desarrollar las sesiones.
- Preparación de los materiales curriculares para la puesta en práctica de las sesiones. Dependiendo de los cuentos se han elaborado planetas, una lengua gigante que en la sesión se ha ido completando con papilas gustativas (gomets de colores), fotos plastificadas para simular el fondo marino, etc. (ver figura 1).

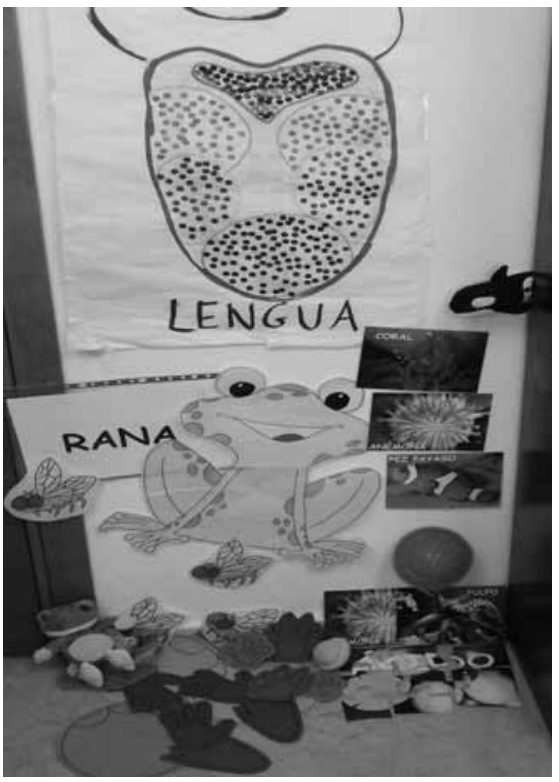

Figura 1.Algunos materiales curriculares elaborados (Fotografia: Belén Tabernero)

b) Fase de puesta en práctica en el aula y valoración de las sesiones.

Desde febrero a junio se llevaron a cabo 5 sesiones de educación física (de 50 minutos de duración cada una) dentro del proyecto jjugamos a los cuentos? Cada sesión se desarrolló en el momento más acorde con la programación docente que las maestras seguían; según el calendario establecido en la primera fase.

Tras cada sesión se ha realizado una evaluación de la misma por parte del alumnado participante (en la imagen 3 se puede ver un momento de esta evaluación y en la imagen 6 se muestra una ficha de aprendizaje/evaluación como modelo realizada por los niños y niñas al finalizar la sesión práctica), las maestras tutoras y las profesoras externas. Además, al finalizar la aplicación de las 5 sesiones se ha realizado una valoración global del proyecto con las maestras tutoras.

Resultados de la experiencia: ejemplo de una sesión elaborada y descripción de su puesta en práctica

\section{Fase de presentación}

Comenzamos con la lectura del cuento impreso «La estrella que cayó del cielo» (Robson \& Newsham, 2005) con el alumnado sentado en semicírculo alrededor de un pequeño escenario formado por una tela donde se han insertado el fuego, el cielo y los distintos personajes del cuento (hipopótamo, león, elefante, loro, mono). En cada página del cuento los personajes se van moviendo o apropiando de las frases escritas para hacer una representación del contenido escrito.

Tras la lectura del mismo, donde se ha insistido en destacar al protagonista del cuento, en este caso «una estrella», procedemos a realizar la pregunta al grupo: ¿queréisjugar al cuento?

\section{Fase de desarrollo}

VAMOS ALLÁ... «a jugar»:

Siempre es requisito para comenzar a jugar, comprender y/o relacionar algún personaje, escenario o contenido del cuento con el «juego pedagógico» que hemos diseñado para después. Por eso, realizamos una lluvia de preguntas, donde los niños y niñas irán construyendo las respuestas y nosotras iremos orientando. (En el ejemplo que estamos describiendo, deben identificar que la estrella podría ser el Sol y éste está 
inmerso en el Sistema Solar).

¿Os acordáis de la estrella del cuento? ¿Quién sabe el nombre de alguna estrella? Dejaremos que los pequeños digan nombres, hasta que alguno/a indique Sol. En ese momento, centraremos la atención en la estrella Sol, para relacionarla con otros elementos que ellos pueden ir diciendo y nosotros orientando:

¿Es una estrella importante para nuestro planeta (la Tierra)?

¿Por qué lo es? Luz y calor a la Tierra.

ACTIVIDAD 1. El Sol, da calor a la Tierra. Sin embargo, sus rayos pueden llegar a ser perjudiciales para la salud porque si no nos protegemos podría quemar nuestra piel. Por ello, es importante proteger nuestro cuerpo (ojos, cabeza y piel) del sol cuando más calienta (mediodía).

El primer juego consiste en que hay una persona (se le entrega la estrella para que la lleve) que va a presentar al Sol. Todos los demás estamos por la calle caminando en verano, pero el sol intenta con sus rayos cogernos y nosotros caminamos rápido para evitarlo. $\mathrm{Si}$ alguien es tocado o cogido por el sol, será quemado y debe quedarse inmóvil hasta que su piel se recupere. La piel se recupera cuando la crema solar (representada por otro jugador designado al principio del juego) pasa frotando nuestro cuerpo y nos da factor de protección para poder seguir paseando con los rayos del sol. Insistimos en la importancia del hábito de protegerse del sol, especialmente en los momentos donde más intensidad tiene para evitar quemaduras en la piel. Sugerimos que nos propongan otros métodos de protección ante el sol: utilizar gorra, jugar bajo una sombra, refrescarnos con agua, etc.

Continuamos con preguntas orientadoras: ¿De qué creéis que está formado el Sol? De las respuestas ofrecidas, vamos orientando hasta llegar a aclarar que el Sol está formado por gases: hidrógeno y helio, fundamentalmente.

ACTIVIDAD 2. El sol, que está formado por gases, quiere cada vez tener más fuerza y para ello intenta «integran» más gas en su interior

El segundo juego consiste en que una persona, va a representar al Sol, y todos los demás van a ser partículas de helio, que están por el espacio. El Sol va a intentar ir «absorbiendo» a las otras partículas, hasta formar una estrella muy grande con todo el helio que está en el espacio. Para ello, va a correr y se va a unir formando una gran cadena con aquellas partículas que vaya cogiendo hasta que todo el grupo de partículas estén formando un único solAl finalizar la actividad, insistimos en recordar los principales componentes del Sol y valoramos lo grande que se hecho el nuestro Sol al incorporar a todas las partículas de helio.

Seguimos la sesión con otra pregunta reveladora: ¿Alguien sabe cómo se llama al conjunto formado por la estrella Sol y los cuerpos que giran a su alrededor? Sistema Solar(Recordamos que los niños y niñas están trabajando el proyecto de «El espacio» en el aula yprecisamente esa semana cada uno ha investigado en colaboración con las familias un elemento presente en el Sistema Solar).

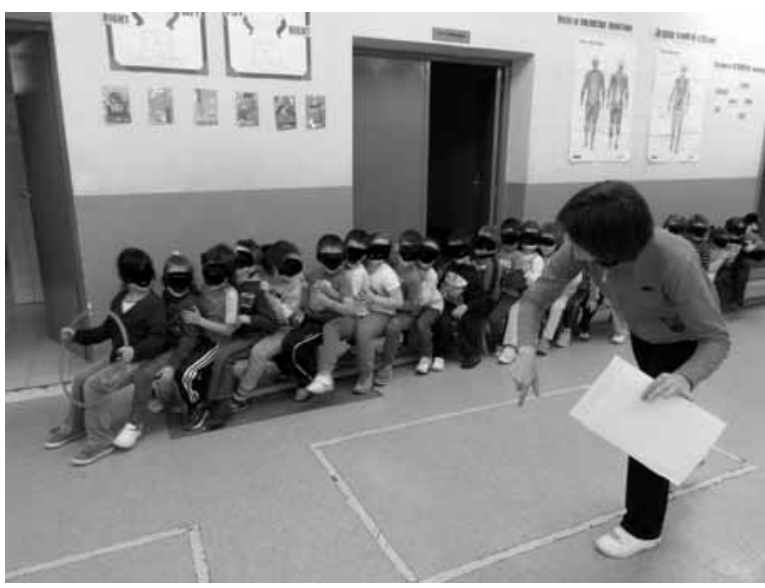

Figura 2. Momento donde todos los participantes colaboran para formar un cohete (Fotografía: BegoñaAliseda)
¿Queréis que hagamos un viaje por el espacio para conocer el Sistema Solar? Para ello, igual que los animales del cuento, necesitaremos un cohete, al que nos debemos subir todos y , todos a la vez, tendremos que crear la suficiente energía para que despegue.

ACTIVIDAD 3. Utilizando 2 ó 3 bancos suecos seguidos uno de otro (o unas colchonetas) pedimos al grupo que se siente formando una hilera donde el tronco quede lo más pegado posible entre ellos.

Realizaremos una actividad grupal, donde todos deben realizar el moviendo a la vez, indicando que es necesaria la coordinación del movimiento para que el cohete despegue. Para empezar, pediremos, por ejemplo, que se realicen flexiones y extensiones del tronco, llevándolo hacia delante y hacia atrás. Cuando se consigan realizar 3 flexiones/ extensiones al mismo tiempo, el cohete despegará y nos permitirá llegar al primer planeta (ver figura 2).

Llegamos al primer planeta: Mercurio. Es el planeta de los cráteres y está tan cerca del sol, que gira alredor del mismo muy rápido.

ACTIVIDAD 4. ¿Os gustaría girar como Mercurio? ¿Quién se atreve? Nos podemos poner por parejas y vamos a buscar el equilibrio en la pareja, uniendo nuestras manos y estirando los brazos. En esa posición vamos a intentar girar lo más rápido posible. Giraremos hacia la derecha y hacia la izquierda para evitar marearnos.

Podemos unirnos en grupos más numerosos, de 4 ó 6 personas e intentar también girar lo más rápido posible imitando a Mercurio en su giro alredor de La Tierra. ¿Cómo se gira más rápido, cuando estamos 2 personas o cuando somos más? Los planetas que están más alejados del Sol ¿tardarán más o menos que Mercurio en girar alredor del Sol? ¿de qué dependerá que tarden más o menos tiempoAbandonamos Mercurio dejándolo en una órbita dibujada en el suelo con tiza situada alrededor del Sol.

Volvemos al cohete, para reanudar nuestro viaje al espacio.

ACTIVIDAD 5. Realizaremos una actividad grupal, uniéndola a la anterior Actividad 3 y aumentando su complejidad (si el grupo es capaz de realizar la anterior coordinación); se pedirá que propongan un movimiento sencillo para que todos lo realicen después de la flexión/extensión de tronco (ejercicio 3). Por ejemplo, que se realicen 3 golpeos con el pie en el suelo con la pierna derecha y otros 3 con la pierna izquierda.

Uniendo ambos ejercicios (el de la actividad 3 y el propuesto en la actividad 5) consideramos que hemos realizado el viaje espacial y preguntaremos ¿alguien sabe a qué planeta hemos llegado? ¿Cual es el siguiente planeta del Sistema Solar?

Llegamos a Venus. Es el planeta brillante; cuando por la noche miramos al cielo es fácil verlo. Sin embargo, nos podemos confundir con una estrella porque brilla tanto que se parece. Precisamente como brilla nos permite ver con claridad los colores, como cuando encendemos una bombilla.

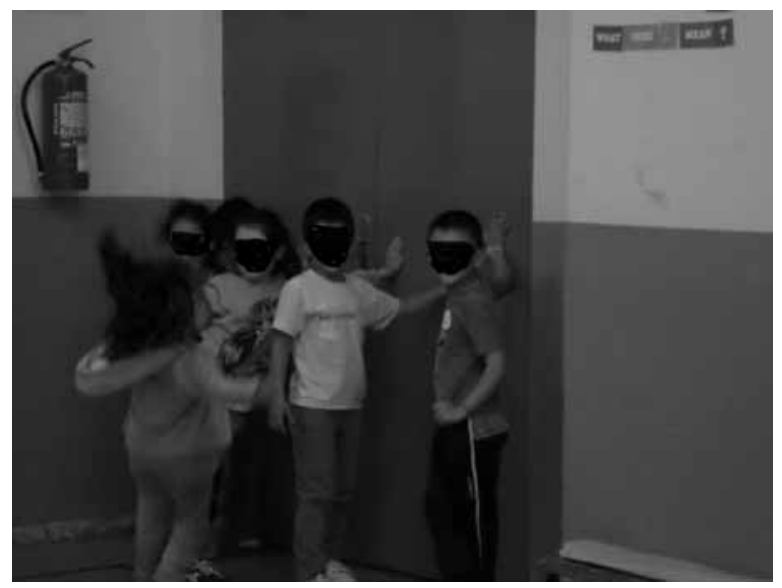

Imagen 3. Momento en que los niños y niñas se dirigían a tocar algo de color naranja. (Fotografia: BelénTabernero) 
ACTIVIDAD 6. Vamos a colocarnos todos alrededor de la persona que tiene aVenus en la mano. Entonces esta persona va a decir: «dhus, Venus de color..naranja» $\mathrm{Y}$ todo el mundo tiene que correr lo más rápido que pueda a tocar algo de ese color (no vale ropa o indumentaria que llevemos puesta). El primero o el más original en tocar algo del color señalado será el que en el turno siguiente elija el color qu®enus iluminará. (Ver figura 3)

Tras dibujar la órbita de Venus y colocarlo en ella, volvemos al cohete para reanudar nuestro viaje al espacio. Aprovechamos el momento de colocación en el cohete para recordar conceptos en relación a los planetas y a los movimientos realizados.

ACTIVIDAD 7. Seguimos con la actividad grupal, uniendo las anteriores ( 3 y 5 ) y proponemos, que digan otro movimiento para unirlo.

Una vez que hemos realizado el viaje espacial, nos bajamos del cohete y llegamos al tercer planeta. Preguntamos de cuál se trata y qué saben de él. Para llegar a desvelar que es la Tierra y que se trata del único con vida. Indagamos acerca de las condiciones necesarias para la vida: agua y temperatura. En La Tierra nos detendremos para hacer 4 actividades:

ACTIVIDAD 8. Nos colocamos haciendo un círculo alrededor del Sol, simulando la órbita que la Tierra describe alrededor del Sol. ¿Cuánto tarda la Tierra en dar una vuelta completa alrededor del sol? Introducimos el concepto temporal de 1 año $=365$ días y vamos girando en el círculo, despacio mientras introducimos que ese movimiento alrededor del Sol se llamatraslación. Durante el recorrido insistimos en que pasamos por las cuatro estaciones, que son las que tiene un año completo. Recordamos cómo giraba Mercurio que estaba muy cerca del Sol y tenía una órbita mucho más pequeña. Comparamos la diferenciamos de girar rápido y lento alrededor del Sol e insistimos en detectar a qué se debe.

ACTIVIDAD 9. Continuamos en círculo, pero en este momento, nos soltamos las manos y vamos a aprender que La Tierra también gira alrededor de sí misma con un movimiento que se llamnotación. ¿Cuánto tiempo tarda la Tierra en girar una vuelta sobre sí misma? Un día $=24$ horas y hay momentos en los que ve al Sol (de día) y momentos en los que no lo ve (de noche). Giramos varias veces, insistiendo en cuándo vemos al Sol (de día) y cuándo no le vemos (de noche). Identificamos los momentos del día donde más sol hace (mediodía $=$ salida del colegio) y menos sol (por la noche $=$ dormimos) y otros intermedios: cuando nos levantamos y vamos al colegio; estamos en el parque o en actividades por la tarde (en estos momentos vemos al sol de reojoNamos indicando distintos momentos del día y los niños y niñas deben girar sobre sí mismos para ver el Sol o no verlo según el momento del día.

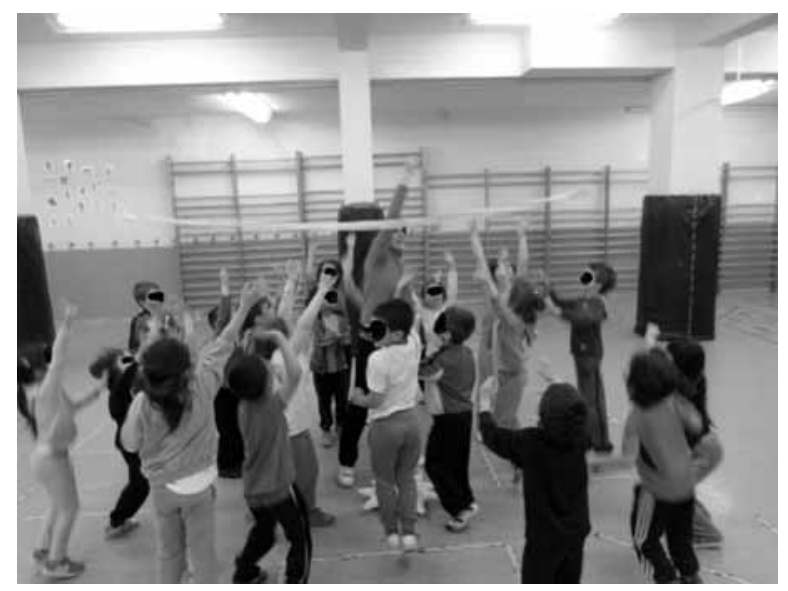

Figura 4. Momento en que los participantes están saltando a coger la cola del cometa (Fotografía: BegoñaAliseda)
ACTIVIDAD 10. Cuando estamos de espalda al Sol (de noche), pedimos a los niños que se tumben para dormir y cierren los ojos. En ese momento, les decimos que hemos vistan cometa o estrella fugaz y que miren hacia arriba a ver si pueden verla. Con una carioca (fabricada con una cabeza -globo con peso- y una cola -papel plateado-) hemos realizado giros encima de sus cabezas pasando por el grupo para que vean la cola y simule una estrella fugaz. ¿Alguien ha cogido alguna vez una estrella fugaz? ¿Queréis intentarlo? Nos colocamos en el medio y quien quiere salta para intentar coger un trocito de la cola del cometa.erminamos la actividad mostrando lo que queda de nuestro cometa (la cabeza y algo de cola) para explicar que los cometas son astros pequeños con una cabeza (formada normalmente por hielo sucio) y una gran cola (ver figura 4).

ACTIVIDAD 11. Ahora estamos sentados alrededor del Sol mirando para él y entonces desde fuera, llegan unos cuerpos (pelotas de goma espuma) que nos golpean suavemente. Se trata deneteoritos que chocan contra la atmósfera de la Tierra y se desintegran cayendo en la Tierra. Las personas que reciben el impacto de un meteorito, pueden levantarse y cogerlo y desde fuera, lanzarlo a otro compañero/a y volverse a sentar en la Tierra. En este «jaleo» de meteoritos, y antes de que lleguen muchos más a La Tierra, dejamos el planeta en el Sistema Solar que estamos dibujando en el suelo y salimos corriendo para subirnos de nuevo al cohete para continuar nuestro viaje por el espacio.

Repasamos en este momento, todos lo que ha sucedido en $\mathrm{La}$ Tierra: hemos girado alrededor del Sol despacio, más distanciados del mismo que desde Mercurio y hemos tardado un año en dar la vuelta; además, hemos visto salir y ponerse el Sol; por la noche, mientras dormíamos, al abrir los ojos hemos visto un cometa y hemos saltado para coger su cola; cuando ya estábamos sentados tranquilos viendo el Sol, han caído meteoritos desde el espacio que golpeaban la corteza de la Tierra y... ahí estamos de nuevo en el cohete.

ACTIVIDAD 12. Retomamos con la actividad grupal, uniendo las anteriores $(3,5$ y 7$)$ y proponemos, por ejemplo, unir 3 chasquidos de dedos realizándolos todos a la vez

Llegamos al cuarto planeta: Marte. Indagamos acerca de características del mismo, hasta que llegamos a definirlo como el planeta rojo.

ACTIVIDAD 13. En Marte realizaremos un juego, similar al juego infantil de «pies quietos» donde una persona se encarga de lanzar Marte al aire. Mientras Marte está en el aire se debe decir el nombre de un compañero/a y éste, debe intentar cogerlo sin que caiga. Si lo recoge, lo vuelve a lanzar y dice el nombre de otro compañero/a y así sucesivamente. Si Marte cae al suelo, todos/as deben huir y el que lo ha cogido del suelo (porque dijeron su nombre) debe decir «Marte rojo»; entonces

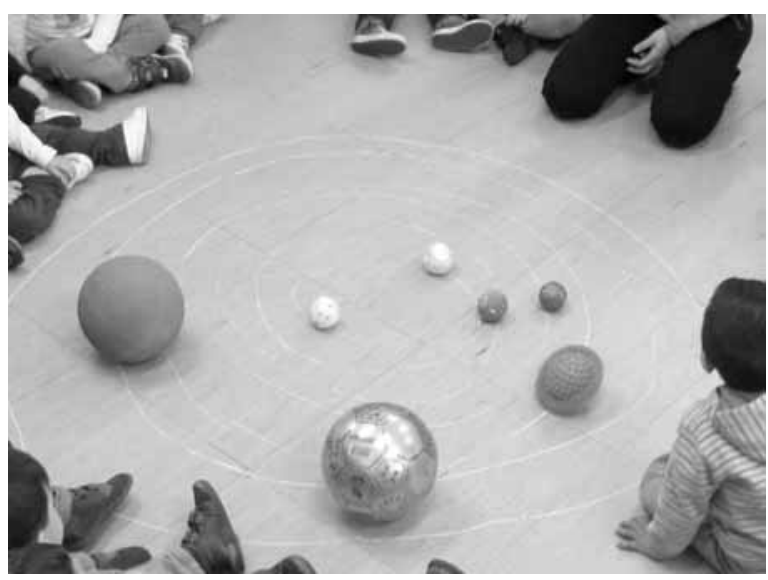

Figura 5. Órbitas dibujadas y materiales curriculares utilizados. (Fotografia: BegoñaAliseda) 
todos se detienen y el receptor puede dar dos pasos indicando en cada paso una palabra «Marte rojo» y lanzar el planeta, para intentar dar a alguno de los compañeros. Si lo hace, será el que lanza en la siguiente ocasión; sino seguirá siendo el mismo el que lance.

Continuamos, como en las actividades anteriores dibujando el Sistema Solar en el suelo e incorporando los planetas que vamos visitando. Tal y como podemos ver en la imagen 5 (que muestra el final de la sesión), se ha puesto el sol en el centro y se han ido situando los diferentes planetas alrededor, cada uno en una órbita dibujada con tiza (ver figura 5).

ACTIVIDAD 14. Seguimos con la actividad grupal, uniendo las anteriores $(3,5,7$ y 12$)$ y proponemos, que digan otro movimiento para unirlo.

Llegamos al quinto planeta: Júpiter Es el planeta más grande.

ACTIVIDAD 15. Dejaremos por el suelo varios balones/globos grandes y les pediremos que realicen lanzamientos, como quieran pero comprobando qué pesa más, qué es más grande y con qué material les cuesta más hacer los lanzamientos. Durante la ejecución estamos observando para hacer hincapié en el vocabulario de lanzar, recibir, fuerza según la distancia del receptor, etc.

Tras la visita de Júpiter, dejamos este planeta en el Sistema Solar que estamos construyendo en el suelo y volvemos al cohete.

ACTIVIDAD 16. Seguimos con la actividad grupal, uniendo las anteriores $(3,5,7,12$ y 14$)$ y proponemos, por ejemplo, unir golpeos en la pierna derecha y pierna izquierda

Llegamos al sexto planeta: Saturno. Es el planeta de los anillos.

ACTIVIDAD 17. En Saturno, utilizaremos los aros para identificarlo con un anillo. Pediremos que se desplacen circulando dentro del aro, como si fueran Saturno. Utilizaremos los colores de los aros para trabajar la velocidad de reacción y afianzar la discriminación de los colores; por ello, les indicaremos que deben salir de su aro y buscar otro distinto del mismo color lo más rápido posible.

Colocamos a Saturno en el Sistema Solar dibujando la órbita que describe e iremos rápidamente al cohete para seguir visitando otros planetas.

ACTIVIDAD 18. Seguimos con la actividad grupal, uniendo las anteriores $(3,5,7,12,14$ y 16$)$ y proponemos, por ejemplo, hacer un pequeño masaje en la cabeza de la persona que está sentada delante de nosotros.

Esta vez no nos bajamos del cohete y les presentamos al séptimo planeta Urano. Es el planeta azul. Les preguntamos si conocen algo que haya en la Tierra que sea de color azul claro, igual que Urano. Esperamos respuestas... El mar, el cielo, etc. Y continuamos nuestro viaje por el espacio... Les pedimos que lo recuerden para intentar luego dibujarlo en su ficha de la sesión. También podríamos utilizar este planeta para representar con su cuerpo estos elementos que indican.

Aunque no salen del cohete, depositamos a Urano en el Sistema Solar que estamos dibujando para que visualicen la órbita que describe este planeta e insistimos en darle referencias para que lo recuerden en relación a elementos azules que ellos conozcan.

ACTIVIDAD 19. Ampliamos la actividad grupal que hemos venido realizando al sentarnos en los bancos suecos desde el principio, uniendo las anteriores $(3,5,7,12,14,16$ y 18$)$ y proponemos, que digan otro movimiento para unirlo.

Llegamos al octavo planeta: Neptuno. Es el último planeta; el más alejado del sol. ¿qué puede significar que esté tan lejos? Temperatura, órbita muy grande, etc.

ACTIVIDAD 20. En Neptuno nos colocamos de nuevo en círculo alrededor del sol haciendo un círculo lo más grande que podamos. Les indicamos que como está muy lejos del sol tarda más tiempo que la
Tierra en dar una vuelta alrededor suyo y muchísimo más que Mercurio. ¿Alguien sabe cuánto tarda? 165 años (les recordamos que La Tierra tardaba un año). Les proponemos dar una vuelta, muy despacio, con giros muy lentos alrededor del sol. Les invitamos a cerrar los ojos y caminar dando la vuelta muy muy despacio. Podemos acompañar esta actividad de una música tranquila para facilitar la comprensión de un movimiento lento. Recordamos la diferencia entre lo rápido que giraba Mercurio, lo intermedio de la Tierra y lo lento de Neptuno.

\section{Fase de reflexión.}

La sesión en el aula de Educación Física finaliza sentados alrededor del Sistema Solar que hemos ido construyendo con las diferentes actividades, recordando lo sucedido. Los niños y niñas lanzan ideas con los recuerdos y vamos construyendo una recopilación de conceptos y sensaciones vividas. Insistimos en conceptos propios de educación física (giros, lanzamientos, saltos, movimiento rápido/lento), pero también en otros que están aprendiendo en el aula (nombres de los planetas y otros astros del espacio, movimientos de la Tierra, características de los planetas, etc.) y sensaciones vividas (mareo al girar muy rápido, cohesión de grupo para que el cohete despegara, alegría al ver la cola del cometa brillar, etc.).

Por último, el grupo sube al aula habitual de clases donde realizan una ficha de aprendizaje/evaluación de la sesión práctica (ver figura 6).

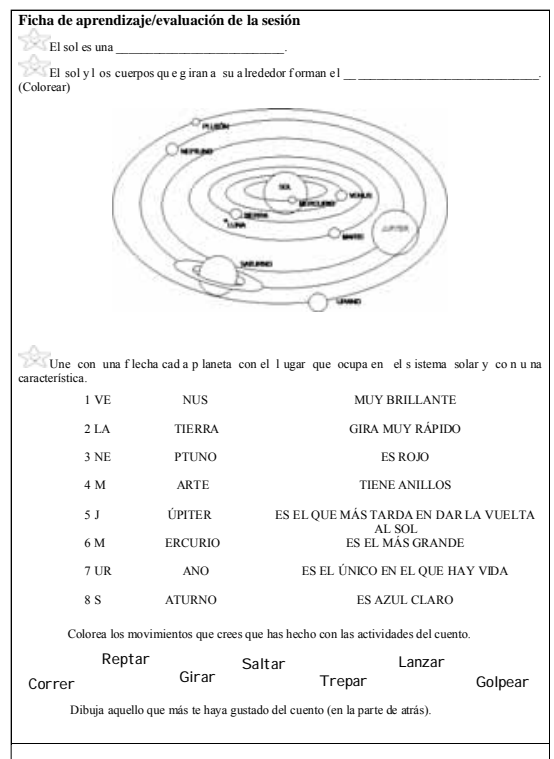

Figura 6. Ficha de aprendizaje/evaluación de la sesión.

\section{Reflexiones/Conclusiones de la Experiencia}

Aunque en este documento hemos intentado describir de forma explícita una sesión realizada, las reflexiones y conclusiones que se exponen a continuación se refieran al conjunto de la experiencia:

Creemos que «Jugar a los cuentos» nos ha permitido que los participantes (niños y niñas de 5 años) lleguen a adquirir aprendizajes globales e interdisciplinares a partir del movimiento, porque:

$\rightarrow$ Se han convertido en protagonistas de su aprendizaje, dando respuesta a situaciones problemáticas mediante una interpretación cognitiva y motriz.

$\rightarrow$ La motivación y disposición del alumnado hacia las actividades ha sido muy alta, aspecto éste favorecido por la conexión entre el contenido del cuento y las actividades realizadas.

$\rightarrow$ Aunque los nexos conductores de las sesiones han sido el movimiento corporal y el cuento infantil, se ha podido comprobar el carácter global de los aprendizajes y la relación existente entre todas las áreas de conocimiento. Realmente este método pedagógico introduce contenidos de todas las áreas y facilita la adquisición de objetivos de todas ellas.

$\rightarrow$ Los niños y niñas han representado situaciones de complicada 
explicación teórica, que de este modo se vivencian, asumen y comprenden con mayor facilidad.

$\rightarrow$ Favorecen el desarrollo integral (conocimientos curriculares, habilidades motrices, actitudes, capacidad de resolución de problemas, autonomía personal...), así como relaciones interpersonales y establecen un nexo de unión entre el mundo del niño y conocimientos seleccionados por los adultos para ellos.

Además, los centros educativos han calificado la experiencia como «muy positiva» para el alumnado (ver en la figura 7 un dibujo de agradecimiento realizado por una niña de 5 años) y para el profesorado: ha proporcionado nuevos aprendizajes y reforzado otros incluidos en los proyectos de aula. Queda planteada la propuesta de ampliar el proyecto a otros cursos e incluso a otros centrosAspecto éste que nos lleva a indicar que la colaboración entre personas vinculadas a diferentes instituciones educativas puede resultar realmente enriquecedora en el proyecto de educar a los niños y niñas.

En definitiva, queremos que esta experiencia sea una invitación a la colaboración entre instituciones, entre áreas de conocimiento y entre personas.

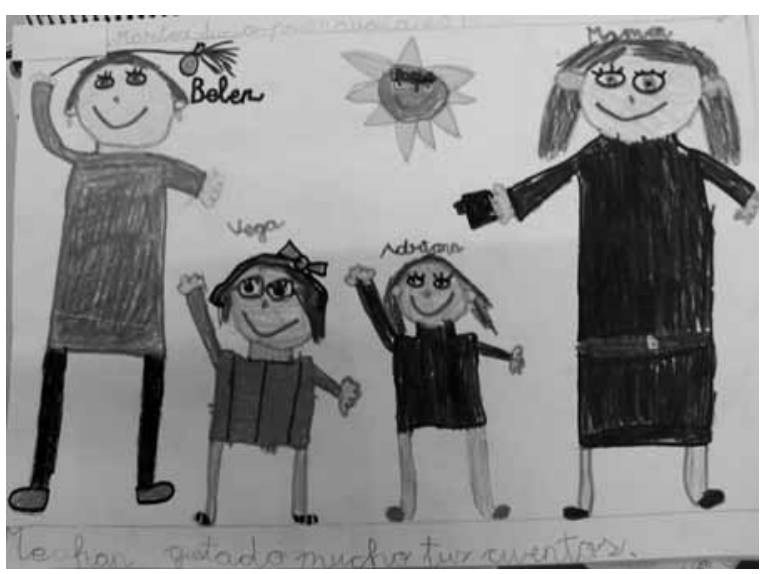

Figura 7. Dibujo de agradecimiento elaborado por una participante.

\section{Agradecimientos}

Este trabajo ha sido subvencionado con un proyecto de Innovación Docente de la Universidad de Salamanca (ID 2013/331) durante el curso 2013/14. Ha sido posible gracias a la colaboración de los niños y niñas de infantil y a sus maestras, nuestro agradecimiento a todos ellos.

\section{Referencias}

Alías, D. (2011). Posibilidades metodológicas del cuento motor en educación infantil y primaria: aproximación teóricaAutodidacta, 5 , 62-69.

Andrae, G. (2013). Las jirafas no pueden bailar. Madrid: Bruño.

Barrio (del), D., Bustamante, R., Calzado, M.A., Nievas, J.M., Palomo, S., Prieto,A., Quiroga, J.J., Rodríguez,V.M., Vega, M. \&Veira, E. (2011). Cuentos motores en Educación Física Primaria. Érase una vez en... Educación Física. Barcelona: Inde.

Bravo, E. \& Pagazaurtundua,V. (2003). El cuento motor y el yoga en la enseñanza primaria. Posibilidad de una experiencia interdisciplinar desde la Educación Física. Apunts: Educación Física y Deportes, $72,35-40$.

Cidoncha, V. \& Díaz, E. (2009). La excursión encantada: cuento psicomotor. La Peonza, Revista de Educación Física para la paz, 4, 61-65.

Conde, J.L. (1994). Cuentos motores. Barcelona: Paidotribo.

Conde, J.;Arteaga, M. \&Viciana, V. (1998). Interdisciplinariedad de las áreas en educación primaria. La Educación Física refuerzo del área de lengua castellana y literatura. Apunts de Educación Física y Deportes, 51, 46-54.

Escalante, D. \& Caldera, R. (2008). Literatura para niños: una forma natural de aprender a leer Artículos arbitrados, 43, 669-678.

García, B.M. \& Pérez, M. (2010). Cuento motor: «Una pizca de ma- gia». Revista EFDeportes.com, Revista Digital, 149. Recuperado de http://www.efdeportes.com/efd149/cuento-motor-una-pizca-demagia.htm

García, E. (2011). El cuento motor, el cuento movido. Revista EFDeportes.com, Revista Digital, 155. Recuperado de http:// www.efdeportes.com/efd155/el-cuento-motor-el-cuentomovido.htm

González, R.; Madrera, E., \& Salguero,A. (2004). Las escuelas gimnásticas y su relación con la actividad física y educación física actuales. Revista EFDeportes.com, Revista Digital, 73. Recuperado de http:/ /www.efdeportes.com/efd73/gimn.htm

Grejniec, M. (2011). ¿A qué sabe la luna? Pontevedra: Kalandraka.

Guimaraes, R. (2009). ¿Qué puede aportar la literatura infantil a una educación física para la paz? «La peonza»-Revista de Educación Física para la paz, 4, 87-97.

Iglesia, J. (2008). Los cuentos motores como herramienta pedagógica para la Educación Infantil y Primaria. Revista de comunicación y nuevas tecnologías ICONO14, 10, 1-15.

Lionni, L. (1982).Nadarín. Barcelona: Lumen.

Marshall, M. (2006). Leoncito se ha perdido. Madrid: Artime.

Méndez-Giménez, A. \& Fernández-Río, J. (2013). El diseño de cuentos motores en la formación inicial del profesorado asturianoAnálisis de las creencias de los estudiantes desde la perspectiva construccionista. Revista de Investigación en Educación, 11 (2), 111-122.

Otones, R. \& López-Pastor, V. (2014). Un programa de cuentos motores para trabajar la motricidad en educación infantil. Resultados encontrados. «La peonza»-Revista de Educación Física para la paz, 9, 27-44.

Padial, R. \& Sáenz-López, P. (2013). Los cuentos populares/tradicionales en educación infantil. Una propuesta a través del juego. E.motion. Revista de Educación, Motricidad e Investigación, 2, 3247.

Parra, J. (2008). Animación a la lectura a partir del área de Educación Física (los cuentos motores). Revista EFDeportes.com, Revista Digital, 122. Recuperado de http://www.efdeportes.com/efd122/ animacion-a-la-lectura-a-partir-del-area-de-educacion-fisica.htm

Rivas, E. \& Terroba, J. (2010). Desarrollo de la competencia básica «comunicación lingüística» a través del cuento motor y el cuaderno de alumno en la asignatura de Educación FísicaContextos educativos: Revista de Educación, 13, 155-174.

Robson, I.; Newsham, I. (2005)La estrella que cayó del cielo. Madrid: Artime.

Ruíz-Omecaña, J.V. (2009). Cuentos motores cooperativos para la educación primaria. Ljsalfar y los niños del viento. Barcelona: Inde.

Ruíz-Omecaña, J.V. (2011). El cuento motor en la educación infantily en la educación física escolar. Sevilla: Wanceulen editorial deportiva.

Val, P. \& Laso, S. (2015). El cuento motor en educación infantil. Una propuesta: «El bosque de las Hadas». Revista EFDeportes.com, Revista Digital, 205. Recuperado de http://www.efdeportes.com/ efd205/el-cuento-motor-en-educacion-infantil.htm

Vargas, R. \& Carrasco, L. (2006). El cuento motor y su incidencia en la educación por el movimiento. Pensamiento educativo, 38, 108124.

Victoria, S. \& Pérez, A. I. (2010). Los cuentos motrices en la etapa infantil. Revista EFDeportes.com, Revista Digital, 145. Recuperado de http://www.efdeportes.com/efd145/los-cuentos-motrices-enla-etapa-de-infantil.htm

Villegas, F.\& García, Á. (2010). El cuento motor como recurso para el desarrollo del currículo en el área de Educación Física. Revista EFDeportes.com, Revista Digital, 147. Recurperado de http:// www.efdeportes.com/efd147/el-cuento-motor-en-educacionfisica.htm

Zagalaz, M.D. \& Cachón, J. (2010). Creatividad y metodología activa: aplicación didáctica de un cuento motor . Zapatones. Trances, 2 , 345-358. 